Bryant University

Bryant Digital Repository

Management Department Journal Articles

Management Faculty Publications and

Research

$2-5-2021$

\title{
Recycle System Design for End-of-Life Electronics in Developing Countries
}

Pedro M. Reyes

Jianghong Man

Patrick Jaska

John K. Visich

Bryant University, jvisich@bryant.edu

Michael Gravier

Bryant University, mgravier@bryant.edu

Follow this and additional works at: https://digitalcommons.bryant.edu/manjou

Part of the Business Administration, Management, and Operations Commons, and the Management Sciences and Quantitative Methods Commons

\section{Recommended Citation}

Reyes, Pedro M.; Man, Jianghong; Jaska, Patrick; Visich, John K.; and Gravier, Michael, "Recycle System Design for End-of-Life Electronics in Developing Countries" (2021). Management Department Journal Articles. Paper 85.

https://digitalcommons.bryant.edu/manjou/85

This Article is brought to you for free and open access by the Management Faculty Publications and Research at Bryant Digital Repository. It has been accepted for inclusion in Management Department Journal Articles by an authorized administrator of Bryant Digital Repository. For more information, please contact dcommons@bryant.edu. 


\title{
Recycle system design for end-of-life electronics in developing countries
}

\author{
Pedro M. Reyes \\ Department of Management, \\ Hankamer School of Business, \\ One Bear Place \#98006, Waco, TX 76798-8006, USA \\ Email: pedro_reyes@baylor.edu
}

\section{Jianghong Man}

Center of Sport Industry Studies, Jilin Sport University, 2476 Ziyoudalu Road, Changchun, Postcode: 130022, Jilin, China

Email:manjh@sdu.edu.cn

\section{Patrick Jaska}

McLane College of Business,

University of Mary Hardin-Baylor (UMHB),

900 College Street, UMHB Box 8018,

Belton, Texas 76513, USA

Email: pjaska@umhb.edu

\section{John K. Visich}

Bryant University,

1150 Douglas Pike, Smithfield,

RI 02917-1284, USA

Email: jvisich@bryant.edu

\section{Michael J. Gravier*}

Bryant University,

1150 Douglas Pike, Smithfield,

RI 02917-1291, USA

Email: mgravier@bryant.edu

*Corresponding author

\begin{abstract}
This paper examines recycling of end-of-life products in developing countries to determine the most reasonable collection policy in order to increase profits. The process of self-recycling by original manufacturers is examined using simulations. The simulations were based on three different investment percentages for collection versus refurbishment/remanufacture for
\end{abstract}


end-of-life products. Results offered here can help decision makers understand trade-offs they face as they decide how to best process returned products (refurbish, remanufacture, or recycle). Simulations of the various collection policies for end-of-life products suggest that original manufacturers in developing countries experience better profit results from collection policies that favour developing refurbishment and remanufacturing capabilities over collection. Furthermore, eco-design bolsters profitability and efficiency of self-recycling systems under all conditions, whereas supplier partnership for environmental design only improves outcomes when the original manufacturer invests in its refurbishment and remanufacturing capabilities.

Keywords: simulation; recycle; end-of-life; remanufacture; system dynamics modelling.

Reference to this paper should be made as follows: Reyes, P.M., Man, J., Jaska, P., Visich, J.K. and Gravier, M.J. (xxxx) 'Recycle system design for end-of-life electronics in developing countries', Int. J. Integrated Supply Management, Vol. X, No. Y, pp.xxx-xxx.

Biographical notes: Pedro $\mathrm{M}$. Reyes received his $\mathrm{PhD}$ in Operations Management from the University of Texas at Arlington (UTA). He is an Associate Professor of Operations and Supply Chain Management in the Hankamer School of Business, Baylor University. He is an Erskine Fellow at the University of Canterbury, recognised by the UTA College of Business as a Lawrence Schkade Research Fellow, and is an Associate Editor for the Decision Sciences Journal of Innovative Education. He has more than 50 academic and professional presentations, including international presentations in New Zealand, China, Indonesia, Spain, France, Mexico, Canada, and Argentina. His research has been published in IEEE Engineering Management Review, International Journal of Production Economics, International Journal of Operations \& Production Management, European Journal of Operational Research, Decision Sciences Journal of Innovative Education, Applied Mathematics and Computation, and others. He is also the author of Global Supply Chain Management and RFID in the Supply Chain.

Jianghong Man received her PhD in Management at School of Economics and Management, Southeast University. She was a Postdoctoral Fellow at Shandong University and a visiting scholar at the Hankamer School of Business, Baylor University. She is currently a Professor at Jilin Sport University and the Head of the Sport Industry Research Center there. She also holds the position of PhD Supervisor at Shanghai University of Sport. Her research interests include quantitative sports research and sport industry management. She holds a Chinese National and Provincial Social Science Funds projects as well as a Jilin Education Scientific Planning Key Project and has published in multiple CSSCI journals including Journal of Xi'an Institute of Physical Education, Journal of Shanghai University of Sport, Journal of Wuhan Institute of Physical Education, and Journal of Tianjin University of Sport. She is the author of Analysis of Green Supply Chain Systems.

Patrick Jaska is currently a Professor in the McLane College of Business, University of Mary Hardin-Baylor, Belton, TX, USA. He teaches courses in operations management, supply chain management, and business statistics. He received his Bachelor's and Master's in Mathematics from Baylor University, Waco, TX, USA, and PhD degree from the University of Texas at Arlington, Arlington, TX, USA. His research has been published in Managerial Decision Economics, International Journal of Systems Science, Applied Economics, 
Management Research Review, IEEE Engineering Management Review, and many international journals. His research interests include supply chain management, technology in business applications, and data envelopment analysis.

John K. Visich is a Professor in the Management Department at Bryant University where he teaches courses in operations management, supply chain management, and corporate social responsibility. He has received his $\mathrm{PhD}$ in Operations Management from the University of Houston, and his research interests are in supply chain and healthcare applications of radio frequency identification and supply chain sustainability. He is on the editorial review boards of International Journal of Integrated Supply Management, Decision Sciences Journal of Innovative Education, and International Journal of Operations and Production Management. He has published in International Journal of Operations \& Production Management, European Journal of Operational Research, International Journal of Production Research, and others. He is a two-time winner the DSI Best Teaching Case Award Competition $(2011,2014)$ and he received an Honorable Mention Award for the 2014 Page Prize for Environmental Sustainability Curriculum.

Michael J. Gravier is a Professor of Marketing and Global Supply Chain Management at Bryant University. He has received his PhD from University of North Texas, MS from the Air Force Institute of Technology, and BA from Washington University in St. Louis. His research focuses on supply chain connections including procurement, industrial marketing, and transportation. $\mathrm{He}$ also researches use of technology in supply chains as well as pedagogy.

\section{Introduction}

In increasingly hyper-competitive global markets, firms must evaluate every opportunity to improve their competitive position. Decisions regarding how to handle returned products at the end of their expected lifecycle have too often been viewed primarily through the lens of how to minimise the cost of disposal (Östlin et al., 2009; Aras et al., 2004; van der Laan and Salomon, 1997). The global marketplace places even greater pressures on firms in developing countries that may be at a competitive disadvantage to their international peers. Recycling technologies utilised in developing countries are frequently inefficient. In developed countries, end-of-life electronics can be collected and shipped more efficiently due to advanced collection and recovery techniques. However, in developing countries, used electronics must be processed and disposed of locally. Therefore, a green supply chain management (G-SCM) practice in developing countries would differ from that of developed countries, especially for end-of-life electronics.

Past research has analytically demonstrated that collecting a percent of used products from the end customers increases overall profitability and lead times for manufacturers in a supply chain, especially when firms cooperate to develop reverse logistics processes (Fernando and Tew, 2016; Modak et al., 2016). Empirical evidence summarised in a literature review of the purchasing and supply management literature support the analytical findings regarding the performance benefits of coordinating purchasing strategies with the supplier base (Hochrein et al., 2017). Coordination goes beyond having advanced information technology systems to enable real time information sharing 
- indeed, companies with best-in-class IT that fail to match it with best-in-class business processes actually make less profit and exhibit lower supply chain performance compared to peers who carefully match business processes to technology platforms (Hofmann and Reiner, 2006).

The case of mismatched IT and business processes is especially acute in developing countries where technology is less evenly distributed and business process maturity can vary greatly. Additionally, in developing countries such as China the importance of G-SCM pressures are ranked differently from developed countries. For example, in China central governmental environmental regulations, regional environmental regulations, potential liability and cost for disposal of hazardous materials are the main factors that encourage manufacturers to collect and reuse used products. Most important of all, in developing countries, manufacturers pay more attention to the negative economic performance of G-SCM, such as increased investment in operational costs, training costs, and costs of purchasing environmentally friendly materials (Zhu et al., 2005). Past research has found that the application of life cycle analysis and closed-loop supply chains reduces the overall supply chain cost, in part by making raw materials more plentiful and more available to manufacturing, thereby reducing their costs (Borjian et al., 2019). To date, little research has investigated the design of end-of-life supply chains in the context of developing countries. This paper provides implementation insights in response to past empirical research into G-SCM in a developing nation that called for "...supporting development of a more proactive stance on environmentally oriented organizational practices" [Zhu et al., (2013), p.112].

Of particular interest for this paper is the self-recycle system for electronics, where the manufacturer collects, refurbishes, and remanufactures their own products based on the potential increase in profit resulting from improved eco-design, customer satisfaction, and supplier relationship management. The recycle system for end-of-life electronics can be divided into two systems called social-recycle and self-recycle. The social-recycle system allows for some common disposal of products by end users and output of common raw materials by either government or non-profit organisations. Emphasis is placed on increasing resource efficiency and lowering environmental risk. Recyclers' knowledge about used products is generally less than that of the original manufacturers, who produced the products and can dispose of their products while making better reuse decisions of components. Furthermore, third-party logistics systems are frequently not well established in developing countries.

The self-recycle system is operated by the original manufacturers using specialised technologies for refurbishment and remanufacture focusing on the reuse of used products or used parts and materials. Collecting end-of-life products can be rather costly for the original manufacturers facing pressures to increase profits and market share. Past research has found that higher levels of environment commitment leads to improved reverse logistics effectiveness for repair, refurbishing, and remanufacturing, resulting in reduced scrap and improved delivery time, value recovery lead time, capacity utilisation, and product quality (Fernando and Tew, 2016).

Some research has shown that manufacturers in developing countries do not benefit in economic terms from environmental and G-SCM practices (Bowen et al., 2001; Zhu et al., 2013). This may be in part because developing nations like China depend on informal e-waste recyclers to engage with customers for collecting products and thus their self-recycle practices are underdeveloped (Yu et al., 2010; Chi et al., 2011; Zhu et al., 2013). A meta-analysis of G-SCM in Asian emerging economies found that 
G-SCM practices demonstrate positive economic impact, yet this likely requires properly balancing intra-organisational environment management with supplier integration, eco-design, and customer cooperation (Geng et al., 2017). So far no research has identified the ideal balance of investment policies for reverse logistics to support the electronic recycle system from the manufacturer's perspective in the context of developing nations.

This paper analyses the core decision regarding how to allocate funds to the self-recycle system's collection, refurbishment, and remanufacturing steps. The decision regarding the percentage to invest in each step cannot only decide the contribution to increase profits of this step but also affects the potential profitability of the other steps owing to the complex interactions between firm G-SCM practices and customer likelihood to choose a firm's products, or the availability of funds for refurbish and remanufacture. The paper presents a literature review summarising some relevant research to creating a systems dynamics (SD) model of self-recycling processes and practices, and then a conceptual framework of recycling systems is presented. The decision model for the recycle system model is presented followed by the results and analysis of the simulations' implications. Lastly, conclusions are provided regarding resource allocation into end-of-life self-recycle investment allocation.

\section{Literature review}

Previous research has provided alternative ways to conceptualise possible recycle system design choices. The next subsections review relevant approaches to recycle system design.

The structures required for a reverse supply chain based on remanufacture are more related to network design, demand forecasting and planning, outsourcing and distribution channel planning, eco-product development, and supplier selection at the strategic level (Min and Zhou, 2002). The reasons for starting a reverse-logistics program can be environmental, public opinion, or economic. A well-managed reverse logistics program can bring enormous savings in inventory-carrying, transportation, and waste-disposal costs. When designing a reverse logistics program, the manufacturer must consider other operations which are bound to result in higher costs and missed opportunities for savings and profits (Gooley, 1998).

The biggest question is whether to handle returns internally or externally with a third-party logistics provider. Outsourcing can be an efficient, cost-effective means of keeping the returned goods under control. It allows the manufacturer to focus on core competencies and frees up people to work on products. However, outsourcing depends on the effectiveness and efficiency of the third-party recycler, which is not a mature industry for electronics in developing countries.

\subsection{Product return process}

Implementation of product return processes cannot only save inventory, transportation and waste disposal cost, but could also improve customer loyalty and future sales. Yet, strategic planning of a reverse supply chain network is a major challenge due to the difficulty in actively managing returned products (Pochampally and Gupta, 2005). Zerhouni et al. (2010) divided returned products into good products and new products. 
For good products, the product return flow is independent of the demand flow and the optimal policy is of the base stock type. For new products, demand and returns are strongly correlated and the optimal control problem is more complex. Ramanathan (2011) identified three risk types: low risk, medium risk and high risk products. Data from online customer ratings highlighted that handling product returns played an important role in shaping customer loyalty for low risk products and for high risk products, but not for products that exhibits medium levels of risk. Cannella et al. (2016) analysed the relationship between several reverse logistics factors and order and inventory variance amplification. They found that reducing remanufacturing lead time and increased information transparency led to improved closed-loop supply chain performance. The collection point coverage rate was introduced by Miao et al. (2017) to dynamically adjust the e-waste recycling rate by third party recyclers in a closed-loop supply chain. The model determined the sales rate and market share of various recycling modes and compares the total revenue of the closed-loop supply chain configurations.

Returns are characterised by the uncertainty related to time and quantity because of scarce and unreliable demand data. A graphical evaluation and review technique was applied by Agrawal et al. (2014) to the development of a model for forecasting product returns for mobile phones in India. The model predicts the volume and timing of product returns and was validated through a case study with a leading mobile phone manufacturer in India. While much of the research on product returns is focused on managing returns and expected revenue, Kumar (2017) took a different approach and investigated the consumer selling behaviour for mobile phones. She utilised a survey and the theory of planned behaviour to understand consumer recycling intentions and then through an interview process she developed a reverse supply chain design. Findings indicated that consumer recycling behaviour was mediated by a 'sense of duty' and perceived control.

\subsection{Mathematical programming models}

Inefficient locations for production, distribution, and reverse logistics plants result in excessive direct transportation and negatively impacted production costs, regardless of transportation plans and information sharing policies (Bogataj et al., 2011). Due to the large number of locations and costs associated with a reverse logistics channel a variety of mathematical programming procedures have been developed to facilitate the design of a reverse logistics network.

In order to minimise total costs including reverse logistics shipping cost and fixed opening cost of the disassembly centres and processing centres, Lee and Dong (2008) formulated a mathematical model of a remanufacturing system for a multi-stage, multi-product system with some priority-based conditions for disassembly centres and processing centres. Next, Lee and Dong (2009) proposed a two-stage stochastic programming model for reverse logistics operations under uncertainty for computer products. The first stage consists of building facilities at potential depots with the random parameters with the second stage allocating product flows based on the established network. Lee et al. (2010) extended this research stream of a sustainable logistics network through the development of uncertainty models, such as integrating the sample average approximation scheme with an importance sampling strategy using stochastic programming.

Chaabane et al. (2010) developed a mixed-integer linear programming model that included life cycle assessment principles in addition to the traditional material balance 
constraints at each node in the supply chain. They considered economic cost objectives (location, supply and reverse) and environmental objectives. Their model suggested that environmental legislation must be strengthened and harmonised at a global level in order to drive a meaningful long-term sustainability strategy. Bouzon et al. (2016) used a fuzzy Delphi method and analytical hierarchy process to identify and analyse reverse logistics barriers in the Brazilian electrical-electro equipment industry. They found that economic issues such as tax burden and an uncertain economy were major obstacles to the implementation of reverse logistics. Governance and supply chain processes were the second highest ranked category, while technology and infrastructure ranked third.

A mixed integer linear programming model was developed by Prakash et al. (2017) to identify the variables needed for a closed-loop supply chain. Their results showed that it is critical to identify and manage the risk at various points in the closed-loop supply chain, and the cost to make the supply chain risk averse was insignificant. Though they used an Indian hospital furniture company as a case study, they stated "the approach followed and proposed methodology can be applied to many industries once a firm decides to redesign its supply chain for closing its loop or model under risks" (p.1). Prakash et al. (2020) investigated closed-loop supply chain design using robust optimisation approach for a mixed integer programming formulation to model supply risk, transportation risk and demand uncertainty. They applied their model to product returns for an Indian e-commerce company and found that the integration treatment of risk and uncertainty into the supply chain network design outperformed models that incorporated risk and uncertainty post-ante.

\subsection{Remanufacturing}

In the remanufacturing process, parts are disassembled from recovered products and become new products by combining with other recovered parts or new parts. Kim et al. (2006) proposed a general framework in view of supply planning and developed a mathematical model to optimise the supply planning function. The model determines the quantity of production parts processed in the remanufacturing facilities by subcontractors and the amount of parts purchased from the external suppliers while maximising the total remanufacturing cost saving. Jaber and E1 Saadany (2009) assumed that demand for manufactured items is different from that for remanufactured ones, which resulted in lost sales situations due to stock-out periods for manufactured and remanufactured items. El Saadany and Jaber (2011) considered that each unit of a used product is collected and disassembled into reusable components, where these components are sorted into subassemblies and remanufactured to represent a second source of as-good-as-new units of the end-product. They concluded that not accounting for the disassembled components of a product leads to inappropriate inventory decisions that are not environmentally sound. Jaber and El Saadany (2011) extended their production, remanufacture, and waste disposal model to incorporate learning for both production and remanufacturing processes. Kenné et al. (2012) employed an optimal control theory model using stochastic dynamic programming to deal with the production planning and control of a single product involving combined manufacturing/remanufacturing operations and proposed a policy to minimise the sum of the holding and backlog costs for manufacturing and remanufacturing products.

Acquisition pricing of new or recycled components in a closed-loop supply chain were investigated by $\mathrm{He}$ (2015). The author found that in a decentralised channel 
structure the optimal acquisition price is lower than in integrated recycle channel structure, for both deterministic and stochastic demand cases. This causes a reduction in both recycled quantity and remanufactured quantity, a double-marginalisation effect. Reverse logistics disposition decisions for an Indian cell phone manufacturer were studied by Agrawal et al. (2016). The authors considered five criteria for the disposition decision (economic benefits, environmental benefits, corporate social responsibility, stakeholder's needs, and reverse logistics resources) and five disposition choices (reuse, repair, remanufacturing, recycle, and disposal). They found repair to be the best disposition selection, followed by reuse, if possible. Recycling was preferred over remanufacturing, which was not cost-effective. Disposition decisions for returned electrical and electronic equipment manufacturers in Malaysia were considered by Khor et al. (2016). The authors found that higher levels of disposition performance were attained when regulatory pressure is present. In addition, the recovery of valuable components and remanufacturing were related to enhanced economic and environmental benefits.

\subsection{End-of-life products}

In addition to reverse logistics networks that contains the number and location of thirdparty logistics service providers there are also models for the recycle of end-of-life products. Meade and Sarkis (2002) offered a decision-making framework for selecting and evaluating third-party reverse logistics providers that focused on end-of-life product organisational roles that include recycling and reuse of materials. In a study of recycling models for end-of-life electronics, Lee et al. (2009) discussed the logistics network design for end-of-lease computer products recovery by developing a deterministic programming model for systematically managing forward and reverse logistics flows.

Capraz et al. (2015) investigated the bidding process and operational strategies for a recycling facility that purchases waste electrical and electronic equipment from a municipal collector. Through a case study they analysed three processes: sell to other recyclers; complete disassembly; and bulk recycling. Results showed that profitability of the recycler can be increased when a combination of disassembly and bulk recycling is used for certain items and that when price fluctuations for recovered materials are high the recycler should submit as low of a bid as possible. Reduce, reuse and recycle for household wastes including municipal solid waste, e-waste and vehicles in China were studied by Liu et al. (2017). They concluded that legal frameworks for the circular economy need to be promoted, and that investments should be made in technology innovation and development, and in the construction of more waste treatment facilities.

\subsection{System dynamics}

A SD approach provides the ability to understand the network through the analysis of the interactions between the various components of the integrated system. Strategic decision-makers need comprehensive models to guide them in efficient decision-making that increases the profitability of the entire chain. System dynamics is a good tool for solving this kind of long-term decision making and it can be utilised to analyse and comprehend the dynamic behaviour of supply chains. For the interested readers who wish to know more about SD should see Sterman (2000). 
Using SD, Georgiadis and Vlachos (2004) studied the long-term behaviour of reverse supply chains with product recovery under three ecological awareness influencers:

1 the firm's green image effect on customer demand

2 the take back obligation imposed by legislation

3 government campaigns for proper disposal of used products.

Two years later, they developed another SD model for a single product with remanufacturing activities in the reverse channel (Georgiadis et al., 2006). They analysed capacity planning policies for collection and remanufacturing activities in the reverse channel and assumed that demand may follow different patterns based on standard lifecycle patterns (introduction, growth, maturity, and decline stages). This model was extended to capacity planning of remanufacturing networks for two sequential product-types under two alternative scenarios regarding the market preferences over the product-types (Georgiadis and Athanasiou, 2010). In the first scenario the market is considered showing no preferences and in the second scenario the demand for a product-type can be satisfied only by providing units of the specific type.

Dasgupta et al. (2017) investigated the prediction of e-waste generation in India over a planning period of 2012-2025, and the percentage of this waste through three disposal methods: landfill, second-hand market and recycling. Their study determined that recycle and reuse are more economically beneficial and that the percentage of e-waste sent to landfills will decline over time. The boomerang effect of sale, consumption and return on forecasting, collection, and inventory and production control were studied by Goltsos et al. (2019) for a remanufacturing closed-loop supply chain. The purpose of their research was to understand how different disciplines manage uncertainties in supply, process, demand and control, and they identified multiple directions for future research. A hybrid manufacturing/remanufacturing approach for a closed-loop supply chain was taken by Ponte et al. (2020) who compared their model with a traditional open loop system. They found that the performance of the hybrid model system was heavily influenced by the average return yield and the intrinsic returns volume variability, hence accurate returns forecasting is necessary to decrease system instability. Firms can also engage in proactive communication of returns policy to encourage and control return volumes.

\section{Conceptual framework of recycle system}

In reverse logistics systems design, the focus is on the decision of channels. In those systems, the input variables are usually the forward and backward inventories of different supply chain members such as manufacturers, retailers, collectors, processors and so on. The anticipated output of those systems is minimised total cost. Figure 1 provides an overview of how self-recycle systems and social-recycle systems relate in the overall recycle system for end-of-life electronics.

Through self-collection, refurbishment, disposal and remanufacturing, the end-of-life products can be converted into either re-usable products or useful parts and raw materials. Due to the environmental issues such as take-back obligation imposed by legislation and the green image effect on customer demand, manufacturers are willing to invest into the self-recycle system, which includes three different steps including product collection, 
refurbishment and remanufacture. They must decide the percentage of investment in different steps to maximum benefit and minimise costs. In fact, the investment in each step cannot only decide the contribution to increase profits of this step but also affect the potential increase on profits of other steps.

Figure 1 Recycle system for end-of-life electronics

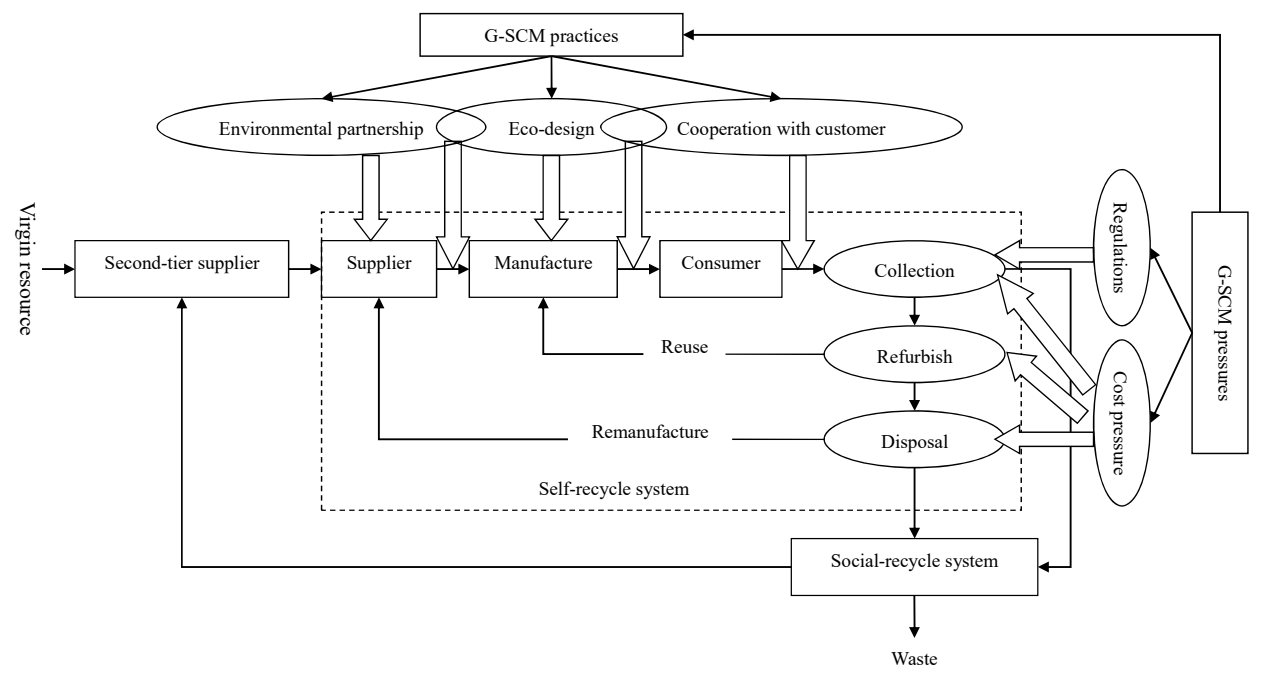

For example, when manufacturers invest a greater percentage of self-recycle money into the market for the collection of used products, the customer may be encouraged to choose the firm's new products, which may lead to a larger market share and more profits from sales. However, a greater percentage invested in collection means relatively less invested on refurbishment and remanufacturing, which can make the reuse of collected products less efficient and could eventually lead to another kind of waste. In order to minimise the risk of this kind of situation, it is important make the relationships among different steps of the self-recycle system clear.

\subsection{Self-collection}

Rapid technology development means fast production changes in the electronics industry. What is high-tech today can be unwanted waste material tomorrow. With regulations getting more stringent and public preferences shifting towards environmental sustainability, manufacturers must be responsive to multiple considerations. The original manufacturers can collect its used electronics at a central warehouse, sort and classify them before refurbishing, remanufacturing, or recycling components. Some of them can be refurbished and resold as new products (or as-good-as-new).

\subsection{Refurbish and reuse}

Depending on the condition and age of the products being returned, manufacturers can then reuse a significant portion of the outdated returned products via the refurbishment process. By testing hardware upgrades and software changes, old products can receive 
new functionality and extended life. The main intention of refurbishment is to convert outdated products into useful ones that can be used in a new market.

\subsection{Disposal and remanufacture}

The collected electronics that cannot be reused by refurbishing can be removed from remanufacture system to the social recycling system, which ensures that the collected productions can be disposed in an environmentally responsible manner. Self-recycle systems provide a complete offering from collecting, refurbishment and remanufacturing any possible parts of end-of-life electronics. With this system, manufacturers can make their operations sustainable and environmentally sound. Moreover, by using social end-of-life recycle activities, manufacturers can achieve savings in time and money.

\section{Methodology}

\subsection{SD decision model of self-recycle system}

In the current model scenario, the relationships between the input (decision of how much to invest in self-recycle) and the output (profitability of the self-recycle process) manifest as a complex interplay that is impossible to solve the problem with mathematical programming methods, and thus considered an NP-hard problem. System dynamics, famously pioneered by Forrester (1958) and sometimes called industrial dynamics, addresses problem solving in living eco-systems where organisations, people, and machines interact, and does so by linking hard control theory with soft system theory (Towill, 1996). SD represents a 'systems thinking' mindset that illuminates insights into underlying causal relationships of complex, nonlinear system, generating knowledge that is readily applicable to improving their operating effectiveness and efficiency (Towill, 1996). Since its inception in the 1950s, system dynamics has informed research and practice in public policy, project management, environment research (most famously by Meadows et al., 1972), and, of course, logistics and supply chains, most famously with the 'Beer Game' (Sterman, 2000). SD modelling is appropriate for elucidating complex systems characterised by nonlinear behaviour, especially when such systems exhibit characteristics of stocks, flows, internal feedback loops, and time delays (Sterman, 2000). Additionally, empirical research has found "...that system dynamics understanding can be viewed as an articulable, method specific but otherwise generalizable form of expertise" [Bendoly, (2014), p.1363].

In the proposed recycle system presented in Figure 1, the percentage of different collection amounts is decided by the original manufacturer's investments in selfcollection. In every period, all the profits of the self-recycling investment are added to the next period of self-recycling. In addition, a fixed amount of funds is invested in the process.

\subsection{Problem description}

Compared with third party collectors, the manufacturer and its retailers can participate in end-of-life reproduction more easily. Furthermore, it can aid in the promotion of new products for the manufacturer if they can encourage consumers to return previously 
purchased products. The collection effort toward returned products can positively affect the sale of new products. However, manufacturers must find the most efficient method for self-recycling. The percentage of investment in self-collection is the first decision to be made and affects the other decisions such as refurbishment and remanufacturing.

Table 1 Table of parameters

\begin{tabular}{ll}
\hline$\alpha$ & Investment percentage of self-collection \\
$\pi_{s e l f-}$ & Total profits of self-recycle system \\
$\pi_{r f}$ & Profits of refurbishment \\
$\pi_{r m}$ & Profits of remanufacture \\
$I_{s e l f}$ & Total investment on self-recycle \\
$I_{c}$ & Investment on self-collection \\
$I_{0}$ & Threshold of investment on self-collection \\
$I_{r f}$ & Investment available for refurbishment \\
$I A_{r m}$ & Investment available for remanufacture \\
$C_{r f}$ & Cost of refurbishment \\
$C_{r m}$ & Cost of remanufacture \\
$U R_{r f}$ & Unit profits of refurbished products \\
$U C_{r f}$ & Unit cost of refurbishment \\
$U C_{v m}$ & Unit cost of virgin parts supply \\
$U C_{r m}$ & Unit cost of reused parts supply \\
$Q_{p}$ & Quantity of end-of-life products \\
$Q_{c}$ & Quantity of self-collected products \\
$Q_{r f}$ & Quantity of refurbished products \\
$Q_{r m}$ & Quantity of reused parts supply \\
$Q_{A r f}$ & Quantity of products can be refurbished \\
$Q_{A r m}$ & Quantity of reusable parts \\
$p_{c}$ & Percentage of self-collection \\
$p_{c m a x}$ & Maximum of percentage of self-collection \\
$p_{r f}$ & Percentage of refurbishment \\
$f_{c}($ ) & Quantity function of collected products \\
$f_{r f}($ ) & Quantity function of refurbished products \\
$f_{r m}()$ & Quantity function of remanufactured products \\
$f_{A r f}()$ & Quantity function of products can be refurbished \\
$f_{A r m}()$ & Quantity function of reusable parts \\
\hline
\end{tabular}

The factors that can affect the decision of investment percentages of self-collection and their related activities are described in Figure 2 (causal loop diagram of investments in self-recycle). This is followed by Table 1 (table of parameters) that lists and defines the model parameters. A discussion of the relationships among the variables follow in the next section. 
Figure 2 Causal loop diagram of investment in self-recycle

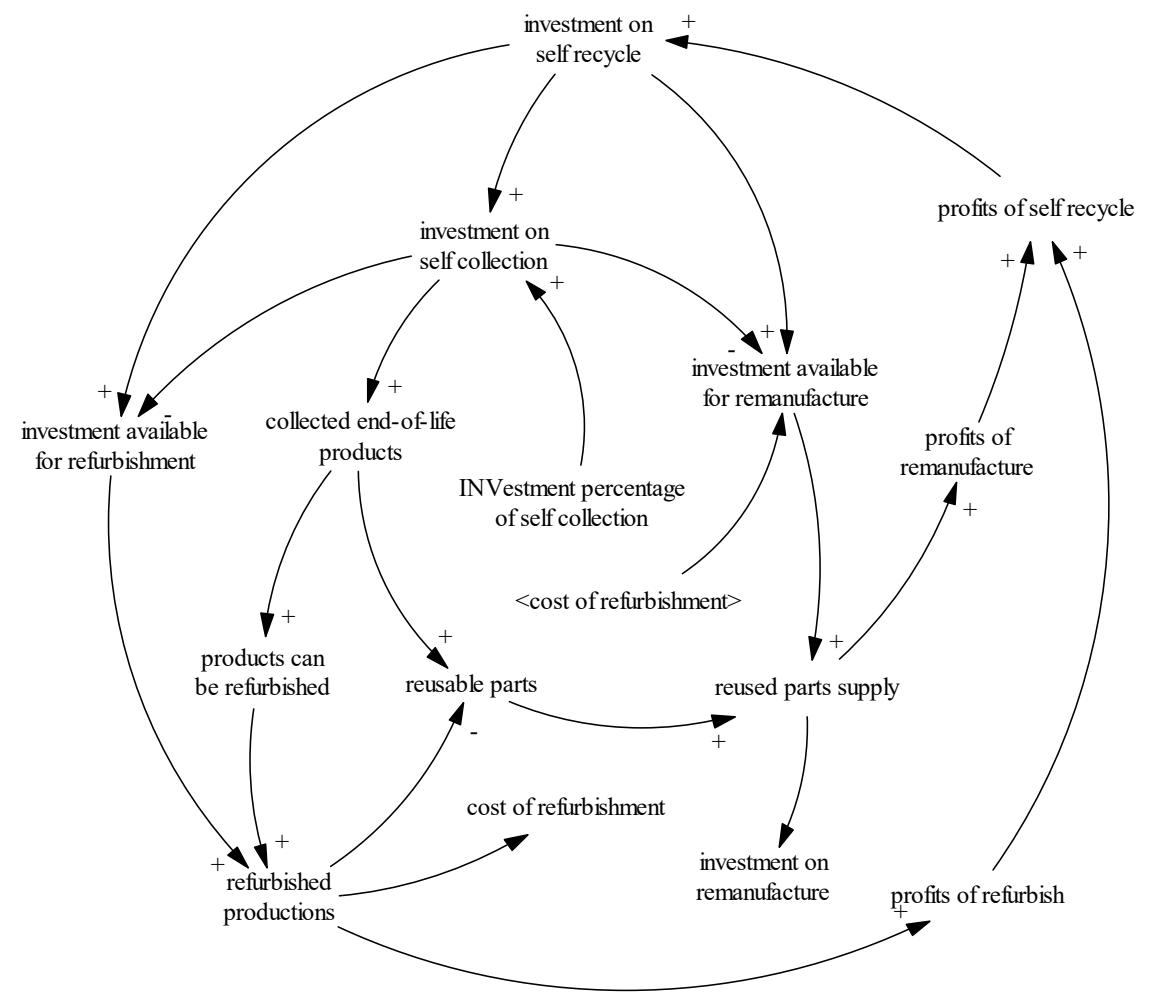

\subsection{Structural equation model}

The total profit of self-recycle system is expressed as:

$$
\pi_{\text {self }}=\pi_{r f}+\pi_{r m}
$$

Profits in equation (1) depend on the investment in self-collection, the investment in refurbishment and the investment in remanufacturing. The following is a discussion of the relationships between self-recycling profits and different investment decisions.

In Figure 2, the investment in collection $I_{c}$ is

$$
I_{c}=I_{\text {self }} \cdot \alpha
$$

where $\alpha$ is the investment percentage of self-collection, $I_{\text {self- }}$ is total investment on self-recycling.

Quantity of self-collected products $Q_{c}$ is decided by the investment in self-collection $I_{c}$ and the quantity of end-of-life products $Q_{p}$

$$
Q_{c}=f_{c}\left(I_{c}, Q_{p}\right)
$$

The raw material and parts in our model have only two sources: virgin materials/parts and reused materials/parts. The purchase costs of these materials/parts are all known. 
Remanufacturing based on reused materials and parts can reduce the cost of original manufacturing based on virgin materials and parts, that is, $U C_{r m}<U C_{v m}$.

The profits of the sale of refurbished products are

$$
\pi_{r f}=U R_{r f} \cdot Q_{r f}
$$

where the quantity of refurbished products $Q_{r f}$ is decided by the quantity of self-collected products $Q_{c}$ and the investment available for refurbishment $I A_{r f}$

$$
Q_{r f}=f_{r f}\left(Q A_{r f}, I A_{r f}\right)=f_{r f}\left(f_{A r f}\left(Q_{c}\right), I A_{r f}\right)
$$

Where investment available for refurbishment $I A_{r f}$ is

$$
I A_{r f}=I_{\text {self }}-I_{c}=(1-\alpha) I_{\text {self }}
$$

As a result, the cost of refurbishment is

$$
C_{r f}=U C_{r f} \cdot Q_{r f}
$$

The profits of remanufacturing are

$$
\pi_{r m}=\left(U C_{v m}-U C_{r m}\right) Q_{r m}
$$

where the quantity of reused parts $Q_{r m}$ is decided by the quantity of self-collected products $Q_{c}$, the quantity of refurbished products $Q_{r f}$ and the investment available for remanufacturing $I A_{r m}$.

$$
Q_{r m}=f_{r m}\left(Q A_{r m}, I A_{r m}\right)=f_{r m}\left(Q_{c}-Q_{r f}, I A_{r m}\right)
$$

The investment available for remanufacturing IArm is

$$
I A_{r m}=I A_{r f}-C_{r f}
$$

From equation (6) and equation (10), we can see that when the percentage of investment in self-collection $\alpha$ increased, both the investment available for refurbishment $I A_{r f}$ and the investment available for remanufacturing $I A_{r m}$ will decrease.

From equation (4) and equation (8), we can see the profits of refurbishment and remanufacturing depend on the available investments and the quantity of self-collected products $Q_{c}$, which is decided by investment in self-collection Ic and quantity of end-of-life products $Q_{p}$, see equation (3). Also, the profits of remanufacturing depend on the quantities of refurbished products.

Furthermore, the values of the parameters in equation (4) and equation (8), such as unit profits of refurbished production $U R_{r f}$, unit cost of virgin parts supply $U C_{v m}$, and unit cost of reused parts supply $U C_{r m}$ are not always constants may vary under varying production conditions. And even under the same production condition, the unit cost or profit may vary depend on the value of other parameters.

The aim is to get a best percentage of self-collection $\alpha$ to maximum the total contribution to profits of self-recycling in equation (1). But as shown in equation (2) to equation (10), the relationships are rather complex between the input $\alpha$ and the output $\pi_{\text {self. }}$. In another words, it is impossible to solve the problem with mathematical 
programming methods, and thus considered an NP-hard problem. Hence, we use SD simulation modelling to evaluate the factors to find opportunities for increasing profits instead of merely looking to minimise the cost of disposal.

\subsection{Loops in simulation model}

There are 12 casual loops for the investment of self-recycle $I_{\text {self }}$ in Figure 2 . Six of them are positive loops and six are negative loops. Using the parameters given in Table 1, the relations among the variables can be described as following.

\subsubsection{Simplest loops with refurbish/remanufacture}

Loop $1 I_{\text {self }-} \rightarrow(+) I A_{r f} \rightarrow(+) Q_{r f} \rightarrow(+) \pi_{r f} \rightarrow(+) \pi_{\text {self- }} \rightarrow(+) I_{\text {self- }}$

Loop $2 I_{\text {self }} \rightarrow(+) I A_{r m} \rightarrow(+) Q_{r m} \rightarrow(+) \pi_{r m} \rightarrow(+) \pi_{\text {self- }} \rightarrow(+) I_{\text {self- }}$

In loop 1 and loop 2 of Figure 2, when the investment on self-recycle $I_{\text {self- }}$ increased according to equation (6) and equation (10), the available investments for both refurbish and remanufacture will increase, which will lead to higher quantities of refurbished and remanufactured products, as shown in equation (5) and equation (9). As a result, the profits of refurbishment $\pi_{r f}$ and the profits of remanufacturing $\pi_{r m}$ will all increase, as shown in equation (4) and equation (8), and then the total profits of self-recycle $\pi_{\text {self }}$ - will increase, which will eventually increase the investment on self-recycle $I_{\text {self- }}$ in the next period.

These two loops describe the simplest relations between the total investments on selfrecycle $I_{\text {self }}$ and profits of refurbish/remanufacture. According to loop 1 and loop 2, the investment on self-recycle $I_{\text {self- }}$ will keep on increasing, this kind of loops are called positive loops. In the coming discussions, the ' $(+)$ ' for all the positive relations is omitted.

\subsubsection{Positive relations between refurbish/remanufacture and self-collection}

Loop $3 I_{\text {self }} \rightarrow I_{c} \rightarrow Q_{c} \rightarrow Q A_{r f} \rightarrow Q_{r f} \rightarrow \pi_{r f} \rightarrow \pi_{\text {self }} \rightarrow I_{\text {self- }}$

Loop $4 I_{\text {self }} \rightarrow I_{c} \rightarrow Q_{c} \rightarrow Q A_{r m} \rightarrow Q_{r m} \rightarrow \pi_{r m} \rightarrow \pi_{\text {self- }} \rightarrow I_{\text {self- }}$

In loop 3 and loop 4 of Figure 2, when the investments on self-recycle $I_{\text {self }}$ increased, the investments on self-collection $I_{c}$ increase. Therefore, the quantities of collected end-of-life products increase, and then the products that can be refurbished $Q A_{r f}$ and remanufactured $Q A_{r m}$ increase, which leads to higher refurbished products $Q_{r f}$ and higher remanufactured products $Q_{r m}$. As a result, the profits of refurbishment $\pi_{r f}$ and remanufacturing $\pi_{r m}$ increase. According to equation (1), the total profits of self-recycle system $\pi$ self- and investment on self-recycle $I_{\text {self- }}$ increase.

The relations between the above various are all positive, therefore, to the investments in self-recycle $I_{\text {self-, }}$ loop 3 and loop 4 are also positive loops.

Next, we describe two negative loops between $I A_{r f}$ and $I_{c}, I A_{r m}$ and $I_{c}$, where there is only one negative relation. 


\subsubsection{Negative relations between refurbish/remanufacture and self-collection}

Loop $5 I_{\text {self- }} \rightarrow I_{c} \rightarrow(-) I A_{r f} \rightarrow Q_{r f} \rightarrow \pi_{r f} \rightarrow \pi_{\text {self }} \rightarrow I_{\text {self }}$

Loop $6 I_{\text {self- }} \rightarrow I_{c} \rightarrow(-) I A_{r m} \rightarrow Q_{r m} \rightarrow \pi_{r m} \rightarrow \pi_{\text {self- }} \rightarrow I_{\text {self- }}$

The negative relation in loop 5 is between the investments in self-collection $I_{c}$ and the available investments in refurbishment $I A_{r f}$. That is, when the investments in self-collection $I_{c}$ increased, as shown in equation (6), the available investments on refurbishment $I A_{r f}$ decrease, which leads to the decrease of total profits of self-recycle system $\pi_{\text {self-. }}$.

According to equation (10), when the investments on self-collection $I_{c}$ increased, the available investments on refurbishment $I A_{r f}$ decrease. This is the only one negative relation in loop 6 , between the investments on self-collection $I_{c}$ and the available investments on remanufacturing $I A_{r m}$, which makes loop 6 as a negative loop.

In another words, if we introduce $I_{c}$ to the simplest loop 1 and loop 2 in Section 4.3.1, we can get negative loop 5 and loop 6 . The negative loops stop the investments on self-recycle from increasing.

\subsubsection{Negative relations between refurbish and remanufacture}

Loop $7 I_{\text {self- }} \rightarrow I A_{r f} \rightarrow Q_{r f} \rightarrow(-) Q A_{r m} \rightarrow Q_{r m} \rightarrow \pi_{r m} \rightarrow \pi_{\text {self- }} \rightarrow I_{\text {self- }}$

In loop 7 of Figure 2, more investments on self-recycle $I_{\text {self- }}$ mean more refurbished products, as analysed in loop 1. However, according to equation (9), the more refurbished products, the fewer reusable components available for remanufacturing, which reduces profits of remanufacturing $\pi_{r m}$, which eventually leads to decrease of new investments on self-recycle $I_{\text {self- }}$.

We have another negative loop between refurbish and remanufacture:

Loop $8 I_{\text {self- }} \rightarrow I A_{r f} \rightarrow Q_{r f} \rightarrow C_{r f} \rightarrow(-) I A_{r m} \rightarrow Q_{r m} \rightarrow \pi_{r m} \rightarrow \pi_{\text {self- }} \rightarrow I_{\text {self- }}$

In loop 8 , more investments on self-recycle $I_{\text {self- }}$ mean more refurbished products; more refurbished products mean higher cost of refurbishment, according to equation (7); higher cost of refurbishment lead to less available investments on remanufacturing [see equation (10)]; less available investments on remanufacturing leads to less remanufactured products [referring back to equation (9)], which eventually leads to decrease of new investments on self-recycle $I_{\text {self }}$.

\subsubsection{Negative relations among refurbishment, remanufacturing and self- collection}

Considering the positive relation between refurbishment and self-collection in loop 3 and negative relations between refurbishment and remanufacturing in loop 7 and loop 8, the negative relationship exists among refurbishment, remanufacturing and self-collection, shown in loop 9 and loop 10.

$$
\begin{aligned}
& \text { Loop } 9 \quad I_{\text {self- }} \rightarrow I_{c} \rightarrow Q_{c} \rightarrow Q A_{r f} \rightarrow Q_{r f} \rightarrow(-) Q A_{r m} \rightarrow Q_{r m} \rightarrow \pi_{r m} \rightarrow \pi_{\text {self- }} \rightarrow I_{\text {self- }} \\
& \text { Loop } 10 \quad I_{\text {self- }} \rightarrow I_{c} \rightarrow Q_{c} \rightarrow Q A_{r f} \rightarrow Q_{r f} \rightarrow C_{r f} \rightarrow(-) I A_{r m} \rightarrow Q_{r m} \rightarrow \pi_{r m} \rightarrow \pi_{\text {self- }} \rightarrow I_{\text {self- }}
\end{aligned}
$$

Considering the negative relationship between refurbishment and self-collection in loop 5 and negative relationship between refurbishment and remanufacturing in loop 7 
and loop 8, a positive relationship exists among refurbishment, remanufacturing and self-collection, shown in loop 11 and loop 12.

Loop $11 I_{\text {self- }} \rightarrow I_{c} \rightarrow(-) I A_{r f} \rightarrow Q_{r f} \rightarrow(-) Q A_{r m} \rightarrow Q_{r m} \rightarrow \pi_{r m} \rightarrow \pi_{\text {self- }} \rightarrow I_{\text {self }-}$

Loop $12 I_{\text {self- }} \rightarrow I_{c} \rightarrow(-) I A_{r f} \rightarrow Q_{r f} \rightarrow C_{r f} \rightarrow(-) I A_{r m} \rightarrow Q_{r m} \rightarrow \pi_{r m} \rightarrow \pi_{\text {self- }} \rightarrow I_{\text {self- }}$

As shown before, loops 1, 2, 3, and 4 are all simple positive loops because there is no negative relation between any two variables. Loop 11 and loop 12, with two negative relations in each loop, are positive loops but different from the former four simple loops. Loop 5 to loop 10 contains six simple negative loops with only one negative relation.

As demonstrated in the equations from the simulations, the decision of self-collection is rather important. That is, when the percentage of investments on collection $\alpha$ is decided, not only the investments on self-collection are determined, but also the collected products and the available investment on refurbishment/remanufacturing are determined. Although the balance between refurbishment and remanufacturing can change based on the proportion between investments on refurbish and remanufacture, this kind of adjustment is limited by available investment on refurbishment/remanufacturing infrastructure.

\section{Findings}

The purpose of this SD model was to get a best allocation of self-recycling funds between self-collection and refurbishment/remanufacturing in order to maximise the profits of self-recycling. This was done by varying $\alpha$ which was defined as the percentage allocated to collection by the manufacturer, with $1-\alpha$ being the amount allocated to refurbishment and remanufacturing. A summary of the findings follows.

\subsection{Original function settings}

Basic functions are set in Table 2.

Table 2 Table of original functions

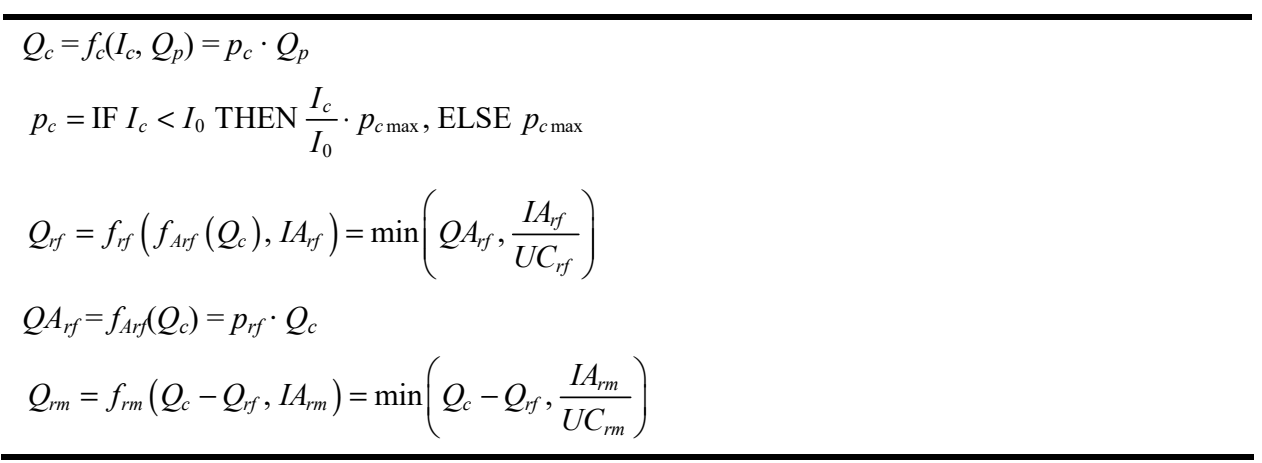

Based on the functions given in Table 2, the stock and flow diagram of self-recycling system is shown in Figure 3. 
Figure 3 Stock and flow diagram of self-recycling system

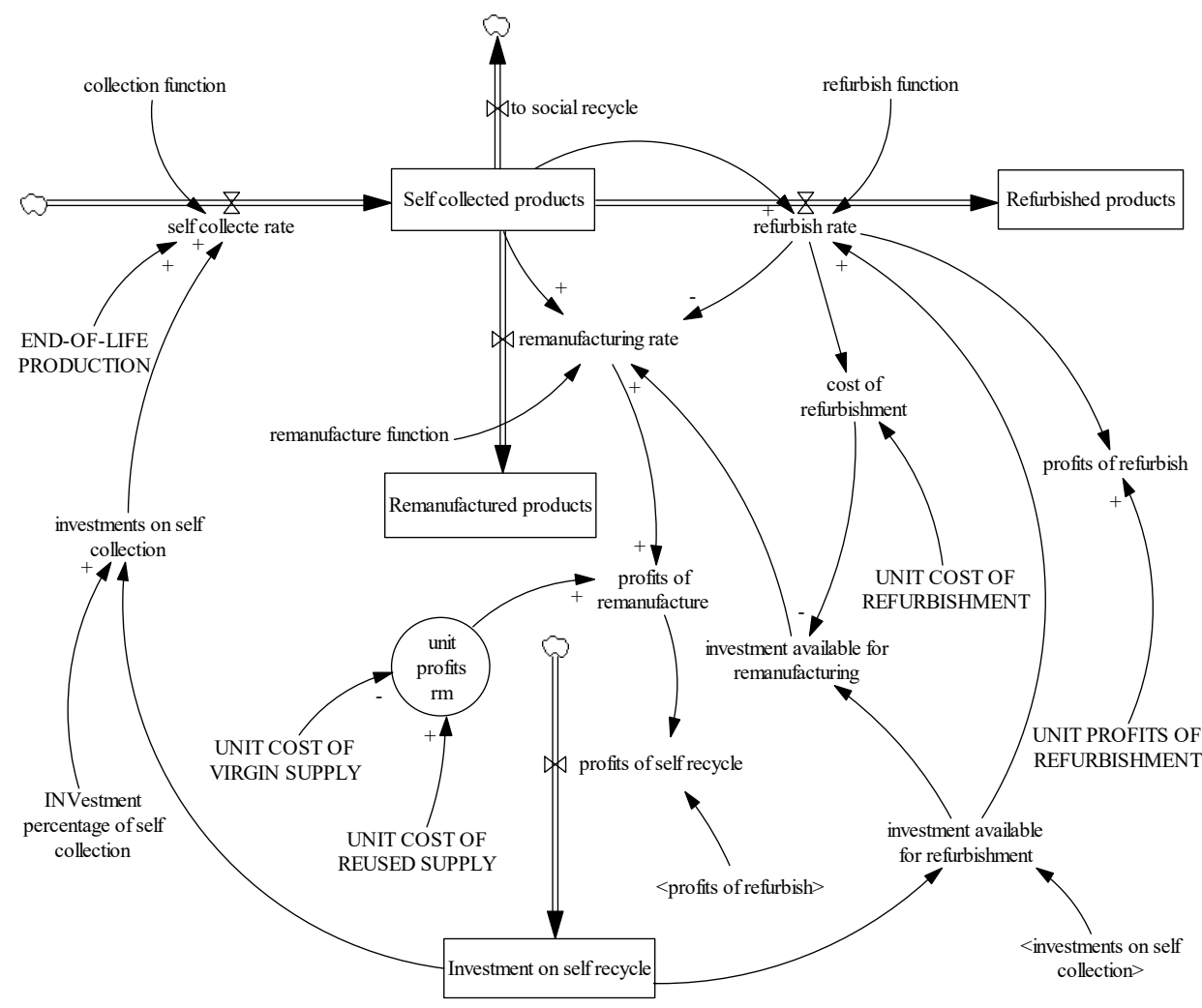

\subsection{Simulations of G-SCM pressures and influences}

The following sections present the results from our simulation of these pressures and influences. Original parameters are given in Table 3.

Table 3 Basic parameters

\begin{tabular}{lc}
\hline Parameters & Original value (Unit: Dollar) \\
\hline$U R_{r f}$ & 10 \\
$U C_{r f}$ & 100 \\
$U C_{v m}$ & 205 \\
$U C_{r m}$ & 200 \\
$I_{s e l f}$ & 100,000 \\
$I_{0}$ & 200,000 \\
$Q_{p}$ & 10,000 (unit: piece) \\
$p_{c \max }$ & $60 \%$ \\
$p_{r f}$ & $20 \%$ \\
\hline
\end{tabular}


In order to depict real-world scenarios and to show the variation in the contribution to profits for different levels of regulation, we use three different collection policies in our model: $\alpha_{1}=35 \%, \alpha_{2}=50 \%, \alpha_{3}=70 \%$. The simulation results are given and discussed as following.

\subsection{Considering the total profits of self-recycling}

Unsurprisingly, Figure 4 shows that when the self-recycling investment percentage allocated to self-collection is the highest $\left(\alpha_{3}=70 \%\right.$ allocated to collection by the manufacturer, the remaining $30 \%$ of self-recycling investment divided between refurbishment by the manufacturer and remanufacture of components by suppliers), the total profits of self-recycling system are the lowest (see line 3 in Figure 4). Focusing heavily on self-collection brings in more product than can be refurbished or remanufactured. The limited funds not obligated to self-collection almost entirely go into refurbishment, with almost no remanufacturing of parts occurring. The number of end-of-life products collected is high, but the profits from refurbishment remain low due to the overall low availability of funds for investment in refurbishment. In this scenario, low profits from refurbishment and remanufacturing leave the profit of self-recycling program as a whole sub-optimised, and the self-recycling program diverts a lot of end-oflife product to social recycling.

Interestingly, when self-recycle investment is evenly split $\left(\alpha_{2}=50 \%\right)$ between self-collection and refurbishment/remanufacture, profit is highest for most of the simulation. This shifts late in the simulation as the scenario with the lowest investment in self-recycling ( $\left.\alpha_{1}=35 \%\right)$ gains greater profits than the $\alpha_{2}=50 \%$ scenario beginning in the 52nd month (see line 1 and line 2 in Figure 4).

Figure 4 Profits of self-recycling system
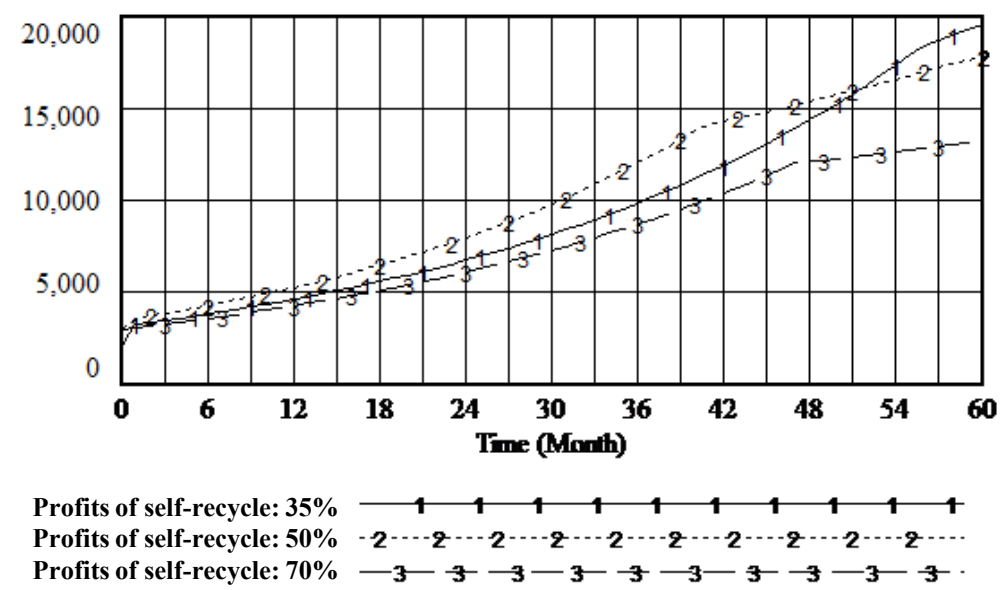

This counter-intuitive finding that the lowest investment in self-recycling returns the overall greatest profitability results from the complex feedback interactions that manifest after the decision of how much to invest in self-collection. When $\alpha_{1}=35 \%$ the investment available for refurbishment $\left(I A_{r f}\right)$ is highest but the reduced investment in selfcollection leads to the lowest quantity of products that can be refurbished $\left(Q A_{r f}\right)$, with 
concomitant reductions to profits (see Figure 5). At the same time, the investments dedicated to refurbishment diminish investments available for remanufacture $\left(I A_{r m}\right)$ but the products that can be remanufactured $\left(Q A_{r m}\right)$ is highest, which leads to the highest remanufacture rate (see Figure 6).

Figure 5 Relations among $Q_{r f}, I_{A r f}$ and $Q_{A r f}$

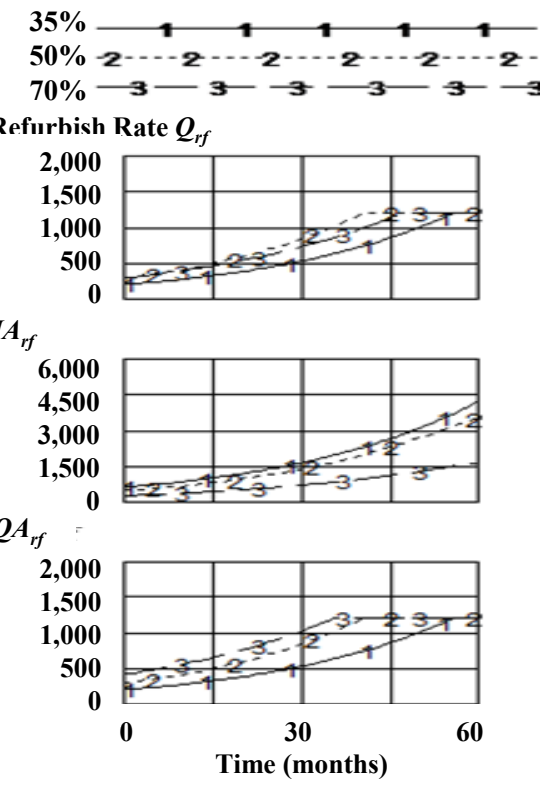

Figure 6 Relations among $Q_{r m}, I_{A r m}$ and $Q_{A r m}$

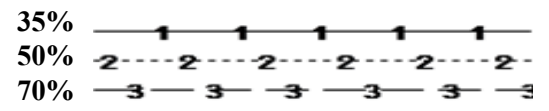

Remanufacturing Rate $Q_{r m}$

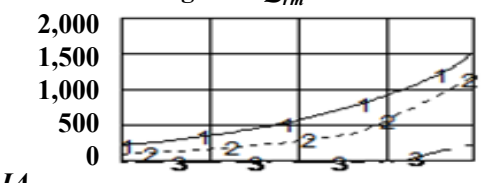

$I A_{r m}$

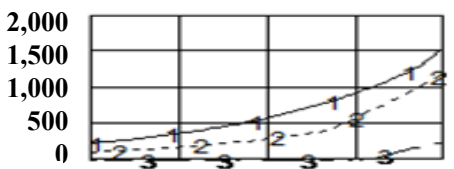

$\boldsymbol{Q} \boldsymbol{A}_{r m}$

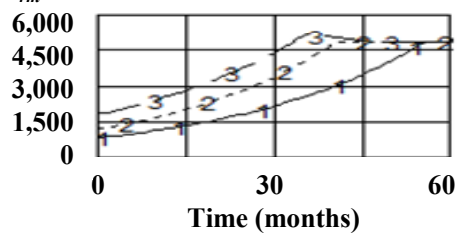


In summary, allocating less to self-collection brings in less product while increasing capacity for the profit-generating activities of refurbishing and remanufacturing. The power of refurbishing and remanufacturing to generate profits for a self-recycling program suggests that designing products with refurbishment and remanufacturing in mind should be effective at making self-collection economically self-sustaining.

\subsection{Considering the efficiency of self-recycling}

End-of-life products can be collected by two channels: original manufacturer and thirdparty collectors. Third party collectors' knowledge about the products is less than that of original manufacturers, and many developing countries do not have advanced third-party logistics industries, often depending on informal e-waste recyclers with underdeveloped capabilities (Zhu et al., 2013; Chi et al., 2011; Yu et al., 2010). As a result, third party collectors may not be the preferred source for returned products. However, since collecting end-of-life products is rather costly for the original manufacturers, the investment on self-collection is not the best choice for all scenarios. Therefore, it is valuable to work out a standard to encourage manufacturers to apply recycling and remanufacturing. The efficiency of self-collection is the sum of all refurbished and remanufactured products divided by the total number of end-of-life products, $\left(Q_{r f}+Q_{r m}\right)$ / $Q_{P}$.

The main results of self-recycling are given in Figure 7 and Figure 8.

Figure 7 Self-collection rate of three policies $Q_{c}$

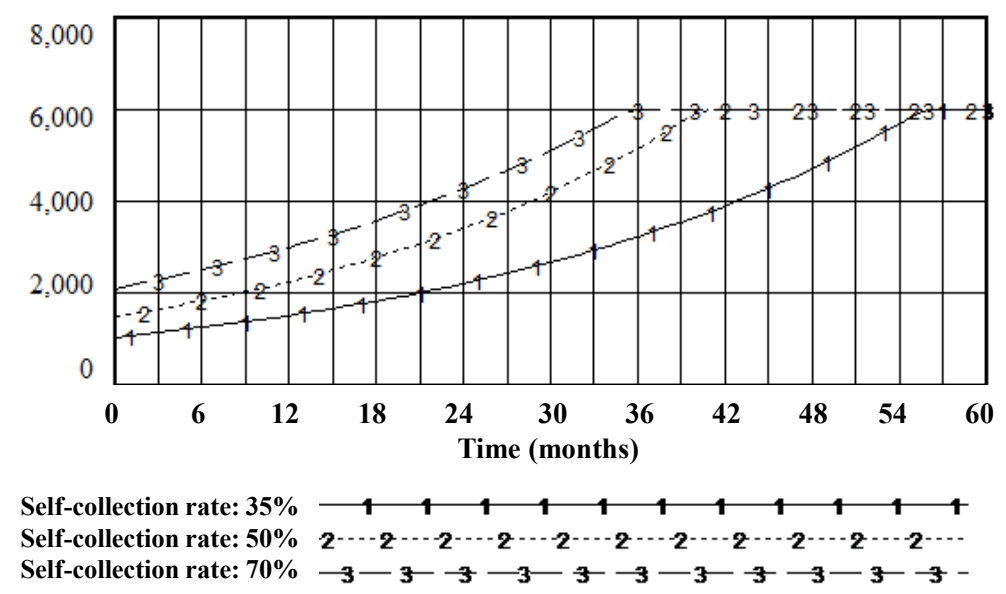

Comparing line 1 in Figure 7 and Figure 8 confirms the link between profitability and efficiency. When the percentage of the investment on self-collecting of used products is high, medium, and low, the amounts of collected products are low, medium, and large, respectively (see in Figure 7). As shown in Figure 8, the efficiencies of self-collection under policies $\alpha_{1}=35 \%$ and $\alpha_{2}=50 \%$ are higher than policy $\alpha_{3}=70 \%$. More investment in self-collection can help a manufacturer collect more used products, but it may not necessarily use all these collected products and/or their components, resulting in a stockpile of excess inventory disposed of via social recycling and generating no profit. 
Figure 8 Efficiency of self-recycling: $\left(Q_{r f}+Q_{r m}\right) / Q_{P}$
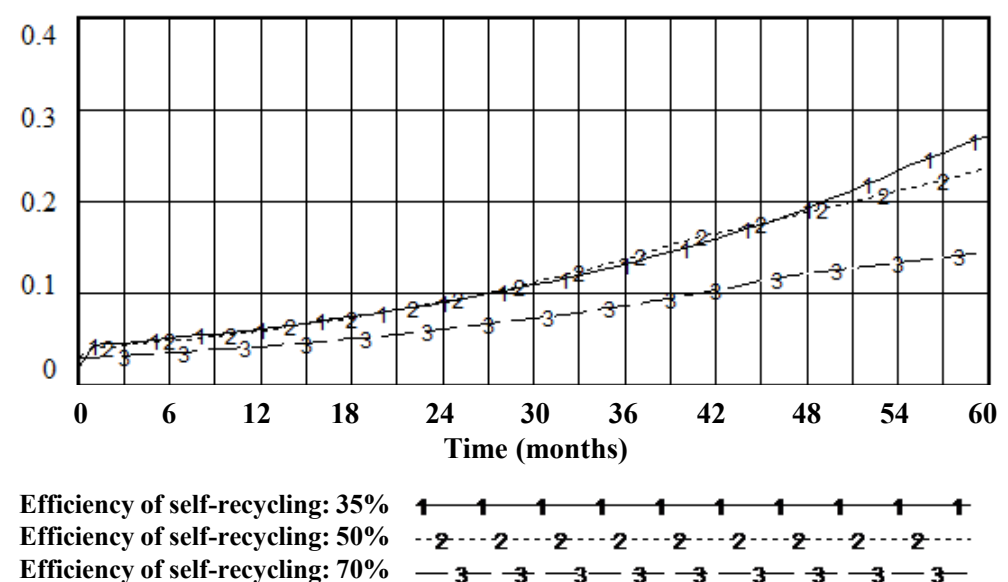

\subsection{Simulations of G-SCM practices}

As shown in Table 2, in the basic simulations, the unit costs of self-collection refurbishment and remanufacturing are all assumed to be constant. As a result, the relationship between costs and quantities is illustrated by line1 in Figure 9.

According to the recycle system for end-of-life electronics as shown in Figure 1, there are many G-SCM pressures, such as cost pressure and regulations, that can lead to G-SCM practices. The relationships between total cost and quantities are not as simple as line 1. For example, the unit costs of self-collection increase sharply when the quantity of self-collected products is increased, which is illustrated by line 2 . Conversely, the unit costs of refurbishment/remanufacture decrease sharply when the quantities of refurbishment/remanufacture increased, as illustrated by line 3 . These lines describe the main elements of G-SCM practices in this model - environmental partnership and ecodesign - and the relationships between these G-SCM practices and total profits and efficiency of the self-recycling system are discussed subsequently.

Figure 9 Different relations between total cost and quantity

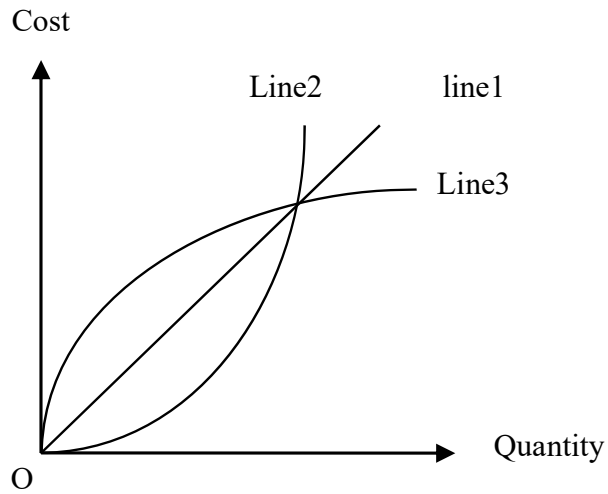




\subsection{Effect of environmental partnership}

Forming environmental partnerships with suppliers is an important supply chain strategy for manufacturers to improve the efficiency of remanufacturing. As seen in equation (8), the costs of refurbishment and remanufacturing are very important for the decision of self-recycling. Only when the unit cost of reused parts and materials is much lower than that of virgin parts and materials is remanufacturing worthwhile. The unit cost of virgin parts supply $\left(U C_{v m}\right)$ and the unit cost of reused parts supply $\left(U C_{r m}\right)$ often vary under different production conditions. The unit cost of remanufacture is assumed to decrease and the relation between total costs and quantities of remanufacturing are described as line 3 in Figure 9. The efficiency of an environmental partnership is given in Figure 10 and Figure 11.

Figure 10 Profits of self-recycling system with environmental partnership
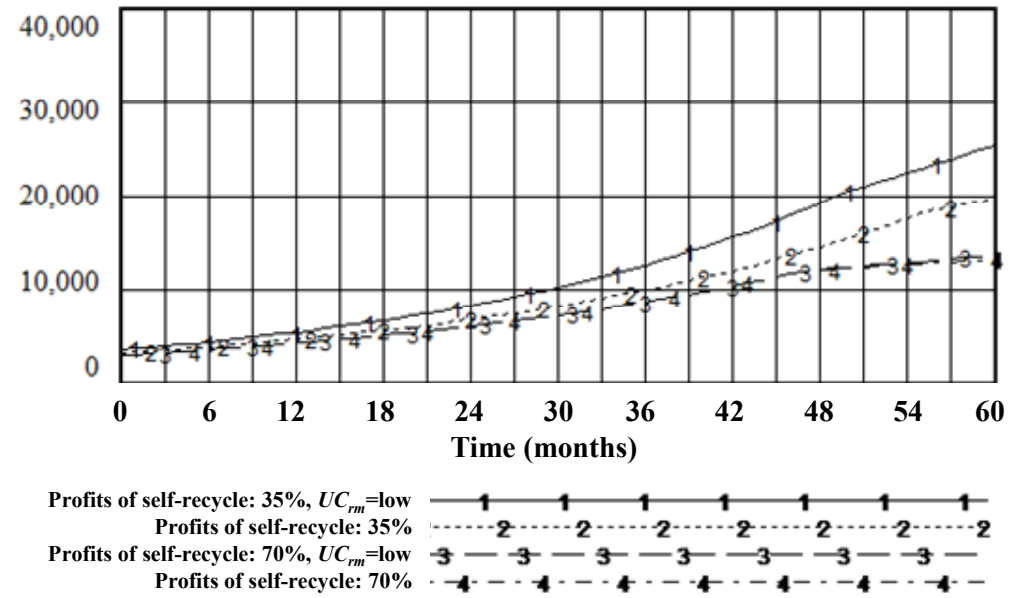

Figure 11 Efficiency of self-recycling system with environmental partnership
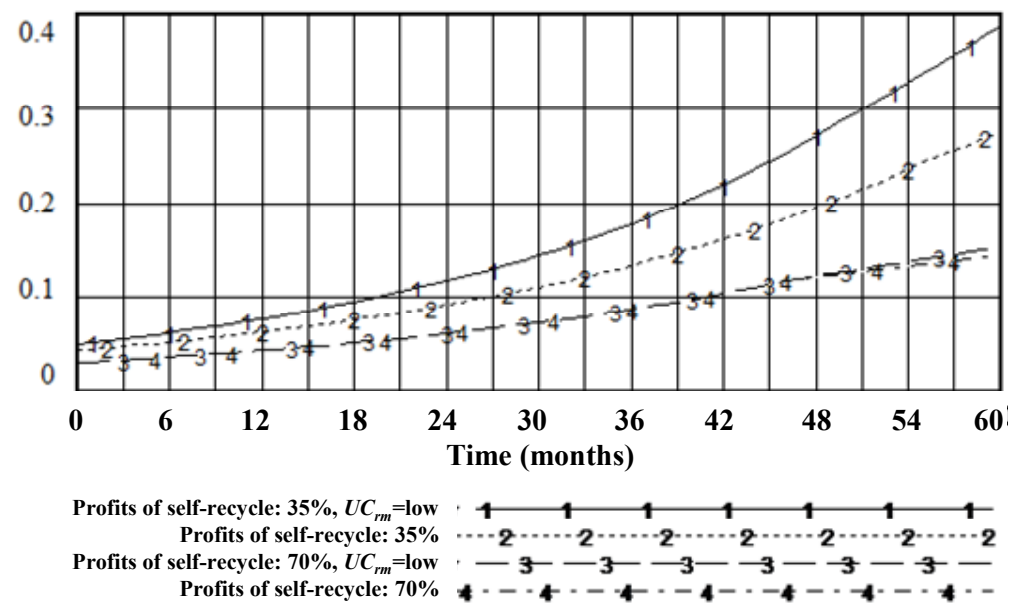
Comparing line 1 and line 2 in Figure 10, in the best basic policy scenario $\left(\alpha_{1}=35 \%\right)$, the profits of a self-recycling system with an environmental partnership (line 1) is higher than the basic condition (line 2). This is because if the manufacturer has a good working relationship with its suppliers, the unit cost of remanufacturing decreases when the quantities of reusable materials and parts increase. The percentage of remanufactured products increases, which eventually leads to higher efficiency of self-recycling (see line 1 and line 2 in Figure 11). On the other hand, in the lowest profit, least efficient policy scenario $\left(\alpha_{3}=70 \%\right)$, there are no improvements on total profits or efficiency with an environmental partnership (see line 3 and line 4 in Figure 10 and Figure 11). In this scenario, the amount of product collected far exceeds the supply chain capacity to refurbish or remanufacture, underscoring the need for the manufacturer to invest adequate resources to remanufacturing and possibly illuminating why some environmental partnerships fail.

\subsection{Effect of eco-design}

In addition to total costs and quantities of refurbishment shown as line 3 in Figure 9, the refurbishment level is also decided by the level of eco-design. Eco-design includes design of products for reduced consumption of material/energy or for reuse, recycling, and recovery of material and component parts. Eco-design can directly reduce the unit cost of refurbishment and remanufacturing, which can eventually increase the profits and efficiency of refurbishment, no matter whether the investment on self-collection is low or high (as shown in Figure 12 and Figure 13).

Figure 12 Profits of recycling system with eco-design
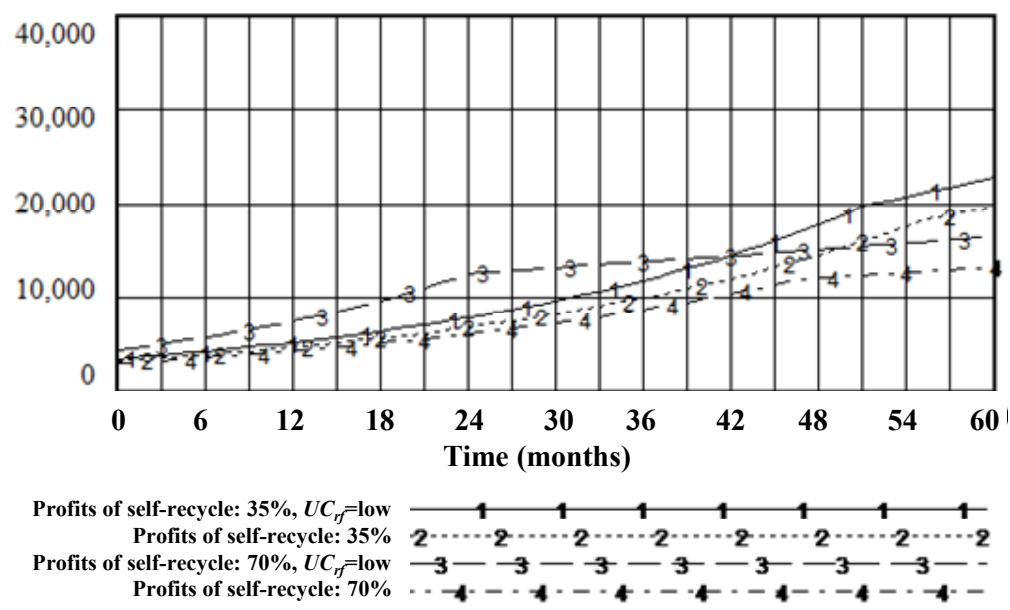
Figure 13 Efficiency of self- recycling system with eco-design
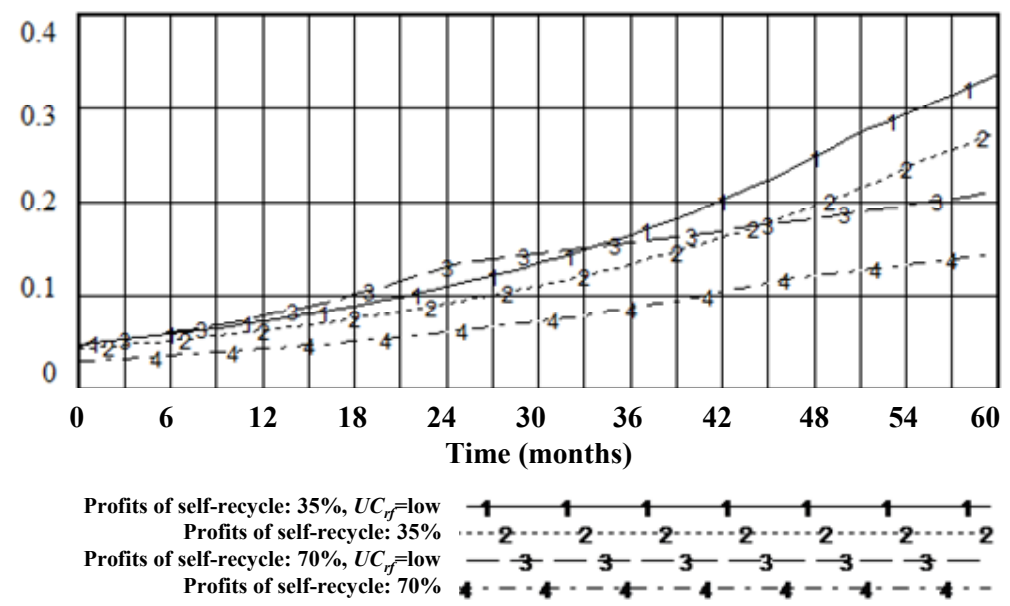

\section{Conclusions}

In this paper, self-recycling of end-of-life products by original manufacturers was analysed using simulations. Results offered here can help decision makers understand trade-offs they face as they decide how to best process end-of-life products (refurbish, remanufacture, or recycle) in developing countries The simulations were based on three different investment percentage collection/remanufacture policies for end-of-life products. The highest profits based on the simulations were seen to be at the low end of investment (35\%). In examining efficiency of in self-recycling, the $35 \%$ and $50 \%$ policies resulted in better efficiencies partially since when too much investment is made in collecting end-of-life products, not all the product collected can be processed through the profit-generating activities of refurbishment and remanufacturing. When suppliers and manufacturers cooperate the unit cost of remanufacturing decreases when the quantities of reusable materials and parts increase. The simulations with a $35 \%$ policy perform the best under these circumstances. Eco-design is another factor that can reduce unit costs and the simulations show that profits increase at any level of policy, suggesting that designing products with refurbishment and remanufacture in mind should be an important strategic imperative, especially as G-SCM regulations become more pervasive in developing countries. It appears that the right product design priorities can return strong profits with minimal investment in recycling.

In summary, the results suggest that original manufacturers in developing countries lacking sophisticated third-party logistics or advanced recycling industries experience better profit results from collection policies that emphasise developing refurbishment and remanufacturing capabilities over self-collection. Eco-design bolsters profitability and efficiency of self-recycling systems under all conditions, whereas supplier partnership for environmental design only improves outcomes when the original manufacturer invests in its refurbishment and remanufacturing capabilities. 


\subsection{Limitations and future research}

SD models provide rich insights and understanding of a plurality of hierarchical and dynamic inter-relationships between variables, factors, actors, policies, and other components of a system, yet they are often criticised for precisely this strength. Unlike more deterministic approaches such as regression, surveys, and optimisation models, SD models cannot provide reductionist, prescriptive results often sought by both practitioners and academic researchers. As such, SD is suitable for exploring policies and strategies (such as the efficacy of information sharing in The Beer Game) but cannot provide precise numerical precision.

Future research should seek to confirm empirically the findings of this SD model. Some research has already found a strong impact from product eco-design yet few studies explore the impacts across the supply chain, and even fewer do so in developing countries. Researchers should also explore the finding that supplier partnership for environmental design only improves outcomes when the original manufacturer invests in its refurbishment and remanufacturing capabilities in order to determine which capabilities and which partnership policies make the biggest impacts. Lastly, it would be interesting to assess more exactly the relative importance of product eco-design versus supplier partnerships under different circumstances. For example, open source designs and use of $3 \mathrm{D}$ printing may improve the impact of supplier relationships relative to eco-design.

\section{References}

Agrawal, S., Singh, R.K. and Murtaza, Q. (2014) 'Forecasting product returns for recycling in Indian electronics industry', Journal of Advances in Management Research, Vol. 11, No. 1, pp.102-114.

Agrawal, S., Singh, R.K. and Murtaza, Q. (2016) 'Disposition decisions in reverse logistics using AHP-fuzzy TOPSIS approach', Journal of Modelling in Management, Vol. 11, No. 4, pp.932-948.

Aras, N., Boyaci, T. and Verter, V. (2004) 'The effect of categorizing returned products in remanufacturing', IE Transactions, Vol. 36, No. 3, pp.319-331.

Bendoly, E. (2014) 'System dynamics understanding in projects: information sharing, psychological safety, and performance effects', Production and Operations Management, Vol. 23, No. 8, pp.1352-1369.

Bogataj, M., Grubbström, R.W. and Bogataj, L. (2011) 'Efficient location of industrial activity cells in a global supply chain', International Journal of Production Economics, Vol. 133, No. 1, pp.243-250.

Borjian, A., Alinezhad, A. and Khalili, J. (2019) 'Closed-loop supply chain considering environmental investment and pollutants emissions', International Journal of Integrated Supply Management, Vol. 12, No. 4, pp.353-374.

Bouzon, M., Govindan, K., Rodriguez, C.M. and Campos, L.M.S. (2016) 'Identification and analysis of reverse logistics barriers using fuzzy Delphi method and AHP', Resources, Conservation and Recycling, March-April, Vol. 108, pp.182-197.

Bowen, F., Cousins, P., Lamming, R. and Faruk, A. (2006) 'Horses for courses: explaining the gap between the theory and practice of green supply', in Greening the Supply Chain, pp.151-172, Springer, London.

Cannella, S., Bruccoleroi M. and Framinan, J.M. (2016) 'Closed-loop supply chains: what reverse logistics factors influence performance?', International Journal of Production Economics, May, Vol. 175, pp.35-49. 
Capraz, O., Polat, O. and Gungor, A. (2015) 'Planning of waste electrical and electronic equipment (WEEE) recycling facilities: MILP modelling and case study investigation', Flexible Services and Manufacturing Journal, Vol. 27, No. 4, pp.479-508.

Chaabane, A., Ramudhin, A. and Paquet, M. (2012) 'Design of sustainable supply chains under the emission trading scheme', International Journal of Production Economics, Vol. 135, No. 1, pp.37-49.

Chi, X., Streicher-Porte, M., Wang, M.Y. and Reuter, M.A. (2011) 'Informal electronic waste recycling: a sector review with special focus on China', Waste Management, Vol. 31, No. 4 , pp.731-742.

Dasgupta, D., Debsarkar, A., Hazra, T., Bala, B.K., Gangopadhyay, A. and Chatterjee, D. (2017) 'Scenario of future e-waste generation and recycle-reuse-landfill-based disposal pattern in India: a system dynamics approach', Environmental Development and Sustainability Journal, Vol. 19, No. 4, pp.1473-1487.

El Saadany, A.M.A. and Jaber, M.Y. (2011) 'A production/remanufacture model with returns' subassemblies managed differently', International Journal of Production Economics, Vol. 133, No. 1, pp.119-126.

Fernando, Y. and Tew, M.M. (2016) 'Reverse logistics in manufacturing waste management: the missing link between environmental commitment and operational performance', International Journal of Integrated Supply Management, Vol. 10, Nos. 3-4, pp.264-282.

Forrester, J.W. (1958) 'Industrial dynamics: a major breakthrough for decision makers', Harvard Business Review, Vol. 36, No. 4, pp.37-66.

Geng, R., Mansouri, S.A. and Aktas, E. (2017) 'The relationship between green supply chain management and performance: a meta-analysis of empirical evidences in Asian emerging economies', International Journal of Production Economics, Vol. 183, Part A, pp.245-258.

Georgiadis, P. and Athanasiou, E. (2010) 'The impact of two-product joint lifecycles on capacity planning of remanufacturing networks', European Journal of Operational Research, Vol. 202, No. 2, pp.420-433.

Georgiadis, P. and Vlachos, D. (2004) 'The effect of environmental parameters on product recovery', European Journal of Operational Research, Vol. 157, No. 2, pp.449-464.

Georgiadis, P., Vlachos, D. and Tagaras, G. (2006) 'The impact of product lifecycle on capacity planning of closed-loop supply chains with remanufacturing', Production and Operations Management, Vol. 15, No. 4, pp.514-527.

Goltsos, T.E., Ponte, B., Wang, S., Liu, Y., Naim, M.M. and Syntetos, A.A. (2019) 'The boomerang returns? Accounting for the impact of uncertainties on the dynamics of remanufacturing systems', International Journal of Production Research, Vol. 57, No. 23, pp.7361-7394.

Gooley, T. (1998) 'Reverse logistics: five steps to success', Logistics Management \& Distribution Report, Vol. 37, No. 6, pp.49-55.

He, Y. (2015) 'Acquisition pricing and remanufacturing decisions in a closed-loop supply chain', International Journal of Production Economics, May, Vol. 163, pp.48-60.

Hochrein, S., Muther, M. and Glock, C.H. (2017) 'Strategy alignment in purchasing and supply management: a systematic literature review and research framework on the performance impact', International Journal of Integrated Supply Management, Vol. 11, No. 1, pp.44-86.

Hofmann, P. and Reiner, G. (2006) 'Drivers for improving supply chain performance: an empirical study', International Journal of Integrated Supply Management, Vol. 2, No. 3, pp.214-230.

Jaber, M.Y. and E1 Saadany, A.M.A. (2011) 'An economic production and remanufacturing model with learning effects', International Journal of Production Economics, Vol. 131, No. 1, pp.115-127.

Jaber, M.Y. and El Saadany, A.M.A. (2009) 'The production, remanufacture and waste disposal model with lost sales', International Journal of Production Economics, Vol. 120, No. 1, pp.115-124. 
Kenné, J.P., Dejax, P., and Gharbi A. (2012) 'Production planning of a hybrid manufacturingremanufacturing system under uncertainty within a closed-loop supply chain', International Journal of Production Economics, Vol. 135, No. 1, pp. 81-93.

Khor, K.S., Udin, Z.M., Ramayah, T. and Hazen, B.T. (2016) 'Reverse logistics in Malaysia: the contingent role of institutional pressure', International Journal of Production Economics, May, Vol. 175, pp.96-108.

Kim, K., Song, I, Kim, J. and Jeong, B. (2006) 'Supply planning model for remanufacturing system in reverse logistics environment', Computers \& Industrial Engineering, Vol. 51, No. 2, pp.279-287.

Kumar, A. (2017) 'Extended TPB model to understand consumer 'selling' behavior: implications for reverse supply chain design of mobile phones', Asia Pacific Journal of Marketing and Logistics, Vol. 29, No. 4, pp.721-742.

Lee, D.H. and Dong, M. (2008) 'A heuristic approach to logistics network design for end-of-lease computer products recovery', Transportation Research Part E: Logistics and Transportation Review, Vol. 44, No. 3, pp.455-474.

Lee, D.H. and Dong, M. (2009) 'Dynamic network design for reverse logistics operations under uncertainty', Transportation Research Part E: Logistics and Transportation Review, Vol. 45, No. 1, pp.61-71.

Lee, D.H., Dong, M. and Bian, W. (2010) 'The design of sustainable logistics network under uncertainty', International Journal of Production Economics, Vol. 128, No. 1, pp.159-166.

Lee, J.E., Gen, M. and Rhee, K-G. (2009) 'Network model and optimization of reverse logistics by hybrid genetic algorithm', Computers \& Industrial Engineering, Vol. 56, No. 3, pp.951-964.

Liu, L., Liang, Y., Song, Q. and Li, J. (2017) 'A review of waste prevention through 3R under the concept of circular economy in China', Journal of Material Cycles and Waste Management, Vol. 19, No. 4, pp.1314-1323.

Meade, L. and Sarkis, J. (2002) 'A conceptual model for selecting and evaluating third-party reverse logistics providers', Supply Chain Management: An International Journal, Vol. 7 , No. 5, pp.283-295.

Meadows, D.H., Meadows, D.L., Randers, J. and Behrens, W.W. (1972) The Limits to Growth, Potomac Associates-Universe Books, New York.

Miao, S., Wang, T. and Chen, D. (2017) 'System dynamics research of remanufacturing closed-loop supply chain dominated by the third party', Waste Management \& Research, Vol. 35, No. 4, pp.379-386.

Min, H. and Zhou, G. (2002) 'Supply chain modeling: past, present and future', Computers and Industrial Engineering, Vol. 43, Nos. 1-2, pp.231-249.

Modak, N.M., Panda, S. and Sana, S.S. (2016) 'Two-echelon supply chain coordination among manufacturer and duopolies retailers with recycling facility', International Journal of Advanced Manufacturing Technology, Vol. 87, Nos. 5-8, pp.1531-1546.

Östlin, J., Sundin, E. and Björkman, M. (2009) 'Product lifecycle implications for remanufacturing strategies', Journal of Cleaner Production, Vol. 17, No. 11, pp.999-1009, http://dx.doi.org/ 10.1016/j.jclepro.2009.02.021.

Pochampally, K.K. and Gupta, S.M. (2005) 'Strategic planning of a reverse supply chain network', International Journal of Integrated Supply Management, Vol. 1, No. 4, pp.421-441.

Ponte, B., Naim, M.M. and Syntetos, A.A. (2020) 'The effect of returns volume uncertainty on the dynamic performance of closed-loop supply chains', Journal of Remanufacturing, Vol. 10, No. 1, pp.1-14.

Prakash, S., Kumar, S., Soni, G., Jain, V. and Rathore, A.P.S. (2020) 'Closed-loop supply chain network design and modelling under risks and demand uncertainty: an integrated robust optimization approach', Annals of Operations Research, Vol. 290, Nos. 1-2, pp.837-864.

Prakash, S., Soni, G. and Rathore, A.P.S. (2017) 'Embedding risk in closed-loop supply chain network design', Journal of Modelling in Management, Vol. 12, No. 3, pp.551-574. 
Ramanathan, R. (2011) 'An empirical analysis on the influence of risk on relationships between handling of product returns and customer loyalty in e-commerce', International Journal of Production Economics, Vol. 130, No. 2, pp.255-261.

Sterman, J. (2000) Business Dynamics: Systems Thinking and Modeling for a Complex World, 1st ed., McGraw-Hill, Boston.

Towill, D.R. (1996) 'Industrial dynamics modelling of supply chains', International Journal of Physical Distribution \& Logistics Management, Vol. 26, No. 2, pp.23-42.

van der Laan, E. and Salomon, M. (1997) 'Production planning and inventory control with remanufacturing and disposal', European Journal of Operational Research, Vol. 102, No. 2 , pp.264-278.

Yu, J., Williams, E., Ju, M. and Shao, C. (2010) 'Managing e-waste in China: policies, pilot projects and alternative approaches', Resources, Conservation and Recycling, Vol. 54, No. 11, pp.991-999.

Zerhouni, H., Gayon, J-P. and Frein, Y. (2010) 'Influence of dependency between demands and returns in a reverse logistics system', International Journal of Production Economics, Vol. 143, No. 1, pp.62-71.

Zhu, Q., Sarkis, J. and Lai, K.H. (2013) 'Institutional-based antecedents and performance outcomes of internal and external green supply chain management practices', Journal of Purchasing and Supply Management, Vol. 19, No. 2, pp.106-117.

Zhu, Q., Sarkis, J., and Geng, Y. (2005) 'Green supply chain management in China: pressures, practices and performance', International Journal of Operations \& Production Management, Vol. 25, No. 5, pp.449-468. 